\title{
Role of intraoperative betablocker for morbid obese patients undergoing laparoscopic bariatric surgery
}

\author{
Ramy Mahrose $^{1 *}$, Wael Elgharabawy ${ }^{1}$ \\ Lecturer ${ }^{I}$, Department of Anaesthesiology, Faculty of Medicine, Ain Shams University, Cairo, \\ Egypt.
}

\section{Background:}

Postoperative pain, nausea, vomiting (PONV) and hypoxia are common in relation to laparoscopic bariatric surgery. Sympatholytic drugs might decrease the need for intravenous or inhalation anaesthetics and opioids and also decrease postoperative adverse events.

\begin{abstract}
Method:
Sixty patients were included. Propofol, fentanyl and rocuronium were used for induction. Study groups were as follows; group E, esmolol infusion was added to sevoflurane and fentanyl, group $\mathrm{N}$ only sevoflurane and fentanyl was used during maintenance of anaesthesia. Patients were monitored during the intraoperative period and postoperatively for $24 \mathrm{~h}$ for analgesic requirements and PONV. Visual analog scale (VAS) scores for pain was also assessed.
\end{abstract}

\section{Results:}

Analgesic and anaesthetic requirements were significantly lower in group E than in group $\mathrm{N}(\mathrm{P}$-value $<0.05)$. VAS scores were significantly lower in group $\mathrm{E}$ than in group $\mathrm{N}$ (Pvalue $<0.05$ ). PONV incidence was significantly lower in group $\mathrm{E}$ than in group $\mathrm{N}$ ( $\mathrm{P}$ value $<0.05)$. Heart rates and blood pressures were significantly lower in group $\mathrm{E}$ compared to group $\mathrm{N}(\mathrm{P}$-value $<0.05)$

\section{Conclusion:}

Using esmolol during anaesthetic maintenance of laparoscopic bariatric surgery significantly decreases anaesthetic and analgesic requirements, postoperative pain, PONV and postoperative hypoxia.

Keywords: Role; beta blocker; morbid obese; laparoscopic; bariatric

\section{Introduction}

Obesity is a major health problem and clearly associated with much comorbidity like coronary artery disease, hypertension, diabetes mellitus, dyslipidaemia, obstructive sleep apnea, and degenerative joint disease. ${ }^{1}$ Bariatric surgeries are significantly increasing as an

*Correspondence: Ramy Mahrose

E mail: ramymahrose2@gmail.com

https://orcid.org/0000-0003-0874-0559 Received: $13 / 01 / 2020$

Accepted: $22 / 04 / 2020$

DOI: http:/doi.org/10.4038/slja.v28i2.8533 effective way of treating morbidly obese patients when other non-surgical options fail. ${ }^{2}$ Opioids given intra-operatively and postoperatively play a major role in postoperative pulmonary morbidity and delay discharge from the hospital. Haemodynamic instability which occurs during the procedure due to insufflation of carbon dioxide and also the surgical interference itself, is a major cause of postoperative nausea and vomiting $(\mathrm{PONV})^{3}$

Esmolol (a sympatholytic agent which is an ultra-short acting selective $\beta 1$ blocker) has been postulated to reduce anaesthetic requirements via a direct anti-nociceptive property. Use of esmolol in patients undergoing gynaecological 
laparoscopic procedures attenuated the increase in HR and MAP intra-operatively, facilitated faster emergence from anaesthesia and significantly decreased postoperative analgesic requirements and time to discharge, without increasing any side effects. ${ }^{4}$

In our study we tried to assess esmolol effects on intra-operative anaesthetic-analgesic needs, postoperative analgesic needs, and postoperative adverse events (PONV and hypoxia) which allow early discharge from hospital and better outcomes.

\section{Patients and methods}

This prospective randomized controlled study was performed on 60 adult patients scheduled for elective abdominal laparoscopic bariatric surgeries under general anaesthesia in Ain Shams University Hospitals. The study was approved by the ethical committee of Ain Shams University.

American Society of Anaesthesiologists (ASA) II patients, with age between 18-59 years, of both genders, with body mass index (BMI) 40$50 \mathrm{~kg} / \mathrm{m}^{2}$ were enrolled in the study and allocated randomly into two groups: group $\mathrm{E}$ (esmolol group) and group $\mathrm{N}$ (non-esmolol group) by computer generated random numbers using numbered sealed envelopes in a double blind manner.

Patients with hepatic impairment, renal impairment, cardiac failure, or respiratory failure and patients with a history of any drug abuse or who were already drug abusers were excluded from the study.

Patients in group E were given a loading dose of esmolol $1 \mathrm{mg} / \mathrm{kg}$ diluted in $50 \mathrm{ml}$ isotonic saline over 30 minutes before anaesthesia induction, then esmolol $10 \mu \mathrm{g} / \mathrm{kg} / \mathrm{min}$ infusion until the end of the surgery. Patients in group $\mathrm{N}$ received $50 \mathrm{ml}$ of isotonic saline over $30 \mathrm{~min}$, followed by an infusion of isotonic saline at same rate of group E till end of surgery. The drugs for infusions were prepared by a medical staff member and the anaesthesiologist who managed the patients during the study was unaware of the patient groupings, and post- operative evaluation was done by a person who did not know what the patient received during the study.

All patients were checked 1 hour before surgery to fulfill the inclusion criteria for the study through history taking, clinical examination, and reviewing results of investigations including complete blood picture, coagulation profile (prothrombin time, partial thromboplastin time and international normalization ratio), serum creatinine, blood urea nitrogen, ALT, AST, random blood sugar, serum electrolytes ( $\mathrm{Na}, \mathrm{K}, \mathrm{Ca})$, arterial blood gases, echocardiography, pulmonary function tests, electrocardiogram and chest x-ray. On arrival to the operating theatre, peripheral intravenous line was secured, and monitoring devices were attached including 5-lead electrocardiography (ECG), non-invasive arterial blood pressure (NIBP), pulse oximetry, end-tidal $\mathrm{CO}_{2}$. Bi-spectral index (BIS) electrodes were placed on the patient's forehead and were connected to BIS Eagle system for monitoring (North American Draeger, USA) to obtain the electroencephalography (EEG) signals before induction of anaesthesia. BIS values between 40 and 60 indicate adequate general anaesthesia. The surface electrodes of peripheral nerve stimulator were positioned over the ulnar nerve area at the wrist, and the forearm was wrapped in acotton blanket to minimize cooling.

Anaesthesia induction was done for all patients by using propofol $2 \mathrm{mg} / \mathrm{kg}$ mixed with lidocaine $20 \mathrm{mg}$ over 20 seconds, fentanyl $1 \mu \mathrm{g} / \mathrm{kg}$, and rocuronium $0.8 \mathrm{mg} / \mathrm{kg}$ to facilitate tracheal intubation. Maintenance of anaesthesia was done by using fentanyl infusion of 0.025 $0.25 \mu \mathrm{g} / \mathrm{kg} / \mathrm{min}$ of ideal body weight (IBW) and sevoflurane $(2-4) \%$ in $100 \%$ oxygen and muscle relaxation was maintained with boluses of rocuronium $10 \mathrm{mg}$ and adjusted to provide complete depression of the first twitch of train of four (TOF) stimulation. Patients were ventilated mechanically to keep end-tidal $\mathrm{CO}_{2}$ $\left(\mathrm{ETCO}_{2}\right)$ between $30-35 \mathrm{mmHg}$. Controlled mechanical ventilation was maintained with tidal volume of 6-8 $\mathrm{ml} / \mathrm{kg}$ IBW and respiratory 
rates $12-14$ breaths/min with positive end expiratory pressure PEEP 5-10 $\mathrm{cmH}_{2} \mathrm{O}$.

Dose adjustment was based on standard haemodynamic measurement and signs of inadequate analgesia, which were defined as heart rate (HR) increase, and MAP over $20 \%$ of baseline values while BIS was recorded between 40 and 60 . This situation of inadequate analgesia was treated by increasing the concentration of sevoflurane by $0.2 \%$, and by giving a supplemental dose of fentanyl 10-20 $\mu \mathrm{g}$ boluses till the haemodynamics returned to targeted values. If BIS was within targeted range and MAP was 20\% lower than baseline or $<60 \mathrm{mmHg}$, patients received $5 \mathrm{mg}$ increments of ephedrine. If there were decreased heart rate to less than 45 beats $/ \mathrm{min}$, i.v. atropine $0.5 \mathrm{mg}$ was given. All infusions and sevoflurane were discontinued with the last skin stitch, and patients were allowed to recover spontaneously, until return of $\mathrm{T} 1=25 \%$ or more than two responses on neuromuscular monitoring. Sugammadex $2 \mathrm{mg} / \mathrm{kg}$ was administered to reverse the residual neuromuscular blockade.

The patients were extubated when BIS value reached 80 and TOF ratio (T4/T1) was $75 \%$ and transferred to post-anaesthetic care unit (PACU) where they were observed for 4 hours to avoid any possible residual drug effects. Level of consciousness, respiratory rate, $\mathrm{SpO}_{2}$, MAP, HR were recorded every 15 minutes in the first hour then every hour for next 4 hours then every 4 hours till the end of 24 hours.Any postoperative complications (e.g. hypotension, bradycardia, nausea, vomiting, somnolence, and respiratory depression) were recorded. If postoperative $\mathrm{SpO}_{2}$ dropped below 92\%, $\mathrm{O}_{2}$ $6 \mathrm{~L} / \mathrm{min}$ was applied to patients. If vomiting occurred granisetron $1 \mathrm{mg}$ intravenously was given. Patients present in the recovery room received tramadol $0.5 \mathrm{mg} / \mathrm{kg}$ if VAS score $\geq 3$. Postoperatively pain was assessed through visual analog scale and recorded 30min after recovery, hourly for $4 \mathrm{~h}$ and every $4 \mathrm{~h}$ for $24 \mathrm{~h}$.

\section{Sample size estimation}

The primary outcome of the study was the analgesic requirements intraoperatively, and based on a study carried out by Ritima et al in $2015^{5}$, a sample size of 30 patients was calculated for each group to achieve a power of 0.8 with $P$ value less than 0.05 and the value of confidence interval was accepted as $95 \%$.

\section{Statistical analysis}

Data analysis was done by IBM computer which were using SPSS (statistical program for social science, version 16). The quantitative variables were demonstrated as mean and standard deviation, while the qualitative variables were demonstrated as numbers and percentages. Statistical analysis was done using statistical tests which included Student's t-test, Chi-square test and table analysis. P-value < 0.05 was considered significant.

\section{Results}

\section{Demographic data:}

There are no significant statistical differences between the two groups as regards gender, age, weight, body mass index and duration of surgery (p- value $>0.05$ ) as shown in Table 1 .

Table 1: Comparison between groups according to demographic data

\begin{tabular}{llll} 
& $\begin{array}{l}\text { Group E } \\
(\mathrm{n}=30)\end{array}$ & $\begin{array}{l}\text { Group N } \\
(\mathrm{n}=30)\end{array}$ & -value \\
\hline Female [No. (\%)] & $19(63.3 \%)$ & $21(70 \%)$ & 0.782 \\
Male [No. (\%)] & $11(36.7 \%)$ & $9(30 \%)$ & 0.782 \\
Age & $31.21 \pm 8.11$ & $32.4 \pm 6.92$ & 0.543 \\
Weight & $135.7 \pm 35.7$ & $131.4 \pm 22.4$ & 0.578 \\
BMI & $47.9 \pm 13.3$ & $45.9 \pm 9.2$ & 0.500 \\
Duration of surgery & $153 \pm 25.5$ & $156.1 \pm 23.5$ & 0.626
\end{tabular}

\section{Heart rate (HR) changes in both groups}

There werea statistically significant difference between two groups regarding HR (P-value < 0.05) after 30min, which is the time for giving the loading dose of esmolol in group E. Also, during the intraoperative period and in the immediate postoperative period till one hour after operation, heart rate was lower 
in group $\mathrm{E}$ than in group $\mathrm{N}$ as shown in Table 2.

Table 2: Heart rate changes in two groups

\begin{tabular}{|c|c|c|c|}
\hline Heart rate & Group E & Group N & p-value \\
\hline Baseline & $86.10 \pm 8.23$ & $88.77 \pm 7.89$ & 0.712 \\
\hline After $30 \mathrm{~min}$ & $64.94 \pm 5.79$ & $91.95 \pm 6.98$ & $0.0001 *$ \\
\hline $\begin{array}{c}\text { After } \\
\text { induction }\end{array}$ & $67.90 \pm 4.69$ & $95.78 \pm 7.88$ & $0.0001 *$ \\
\hline $60 \mathrm{~min}$. & $62.97 \pm 4.15$ & $85.43 \pm 4.17$ & $0.0001 *$ \\
\hline $90 \mathrm{~min}$. & $64.16 \pm 4.21$ & $83.70 \pm 4.18$ & $0.0001 *$ \\
\hline $120 \mathrm{~min}$. & $65.29 \pm 4.26$ & $85.76 \pm 4.29$ & $0.0001 *$ \\
\hline $150 \mathrm{~min}$. & $68.35 \pm 9.84$ & $97.25 \pm 8.03$ & $0.0001 *$ \\
\hline
\end{tabular}

Postoperative

\begin{tabular}{|c|c|c|c|}
\hline Immediate & $71.21 \pm 4.77$ & $98.45 \pm 6.12$ & $0.0001 *$ \\
\hline $15 \mathrm{~min}$ & $71.33 \pm 3.45$ & $99.32 \pm 7.2$ & $0.0001 *$ \\
\hline $30 \mathrm{~min}$ & $75.42 \pm 2.99$ & $97.21 \pm 3.23$ & $0.0001 *$ \\
\hline $45 \mathrm{~min}$ & $80.54 \pm 1.75$ & $93.27 \pm 3.56$ & $0.0001 *$ \\
\hline $60 \mathrm{~min}$ & $82.88 \pm 1.89$ & $90.45 \pm 3.99$ & $0.0001 *$ \\
\hline 2 hours & $86.72 \pm 2.21$ & $87.51 \pm 2.45$ & 0.1949 \\
\hline 3 hours & $86.51 \pm 1.65$ & $87.71 \pm 3.43$ & 0.0895 \\
\hline 4 hours & $85.33 \pm 2.11$ & $86.46 \pm 2.66$ & 0.0735 \\
\hline 8 hours & $87.34 \pm 2.18$ & $88.34 \pm 1.56$ & 0.1167 \\
\hline 12 hours & $87.44 \pm 1.65$ & $88.40 \pm 2.55$ & 0.0887 \\
\hline 16 hours & $88.74 \pm 2.32$ & $89.45 \pm 4.11$ & 0.4133 \\
\hline 20 hours & $89.36 \pm 3.71$ & $90.31 \pm 2.66$ & 0.2590 \\
\hline 24 hours & $90.67 \pm 2.76$ & $91.72 \pm 2.78$ & 0.1847 \\
\hline
\end{tabular}

*P-value $<0.05=$ statistically significant
Mean arterial blood pressure (MAP) changes in both groups

MAP values showed a statistically significant difference between both groups (P-value $<0.05$ ) after giving the loading dose of esmolol, all times during the surgery and also during the first hour in PACU. At these times MAP was lower in group $\mathrm{E}$ than in group Nas shown in Table 3.

Table 3: Comparison between two groups according to MAP

\begin{tabular}{|c|c|c|c|}
\hline MAP (mmHg) & Group E & Group N & $p$-value \\
\hline Baseline & $93.92 \pm 3.15$ & $94.32 \pm 2.92$ & 0.6119 \\
\hline After $30 \mathrm{~min}$. & $78.23 \pm 2.55$ & $95.56 \pm 4.28$ & $0.0001^{*}$ \\
\hline After induction & $80.21 \pm 1.22$ & $97.44 \pm 3.22$ & $0.0001^{*}$ \\
\hline After $60 \mathrm{~min}$. & $79.34 \pm 1.99$ & $87.90 \pm 3.69$ & $0.0001^{*}$ \\
\hline After $90 \mathrm{~min}$. & $77.63 \pm 2.4$ & $86.85 \pm 4.19$ & $0.0001^{*}$ \\
\hline After 120 min. & $78.54 \pm 4.20$ & $85.45 \pm 4.27$ & $0.0001^{*}$ \\
\hline $\begin{array}{l}\text { After } 150 \mathrm{~min} . \\
\text { postoperative }\end{array}$ & $81.56 \pm 4.28$ & $89.07 \pm 4.35$ & $0.0001^{*}$ \\
\hline immediate & $83.66 \pm 3.88$ & $95.34 \pm 3.66$ & $0.0001^{*}$ \\
\hline $15 \mathrm{~min}$ & $85.11 \pm 3.21$ & $96.23 \pm 2.13$ & $0.0001^{*}$ \\
\hline $30 \mathrm{~min}$ & $86.31 \pm 2.43$ & $95.26 \pm 3.95$ & $0.0001^{*}$ \\
\hline $45 \mathrm{~min}$ & $86.98 \pm 2.55$ & $96.67 \pm 2.86$ & $0.0001^{*}$ \\
\hline $60 \mathrm{~min}$ & $87.56 \pm 3.11$ & $94.33 \pm 4.82$ & $0.0001^{*}$ \\
\hline 2 hours & $92.42 \pm 2.11$ & $93.4 \pm 3.68$ & 0.3001 \\
\hline 3 hours & $94.89 \pm 3.12$ & $95.59 \pm 2.43$ & 0.3363 \\
\hline 4 hours & $95.66 \pm 2.98$ & $96.58 \pm 1.83$ & 0.1550 \\
\hline 8 hours & $97.56 \pm 2.77$ & $98.67 \pm 3.28$ & 0.1628 \\
\hline 12 hours & $97.87 \pm 3,12$ & $98.76 \pm 2.79$ & 0.2489 \\
\hline 16 hours & $96.62 \pm 2.42$ & $97.85 \pm 3.23$ & 0.1005 \\
\hline 20 hours & $97.82 \pm 2,56$ & $98.94 \pm 2.63$ & 0.1000 \\
\hline 24 hours & $96.66 \pm 3.22$ & $97.02 \pm 2.52$ & 0.6315 \\
\hline
\end{tabular}

\section{Regarding $\mathrm{SpO}_{2}$ changes in both groups} There was a statistically significant difference between both groups regarding postoperative $\mathrm{SpO}_{2}$ from immediately postoperative, after $15 \mathrm{~min}$ and after $30 \mathrm{~min}$. At these times $\mathrm{SpO}_{2}$ was lower in group $\mathrm{N}$ than in group $\mathrm{E}$ but there was no statistically significant difference between both groups regarding intraoperative $\mathrm{SpO}_{2}$ and the following postoperative readings as shown in Table 4. 
Table 4: Comparison between groups according to $\mathrm{SpO}_{2}$

$\begin{array}{llll}\mathbf{S p O}_{2} & \text { Group E } & \text { Group N } & \text { p-value } \\ \text { Induction } & 95.97 \pm 2.40 & 94.85 \pm 2.37 & 0.0741 \\ \text { After 30 min. } & 95.29 \pm 2.38 & 94.34 \pm 2.38 & 0.1276 \\ \text { After 60 min. } & 95.20 \pm 2.31 & 94.30 \pm 2.33 & 0.1384 \\ \text { After 90 min. } & 94.34 \pm 2.36 & 93.40 \pm 2.36 & 0.1284 \\ \text { After 120 min. } & 94.39 \pm 2.33 & 93.46 \pm 2.33 & 0.1276 \\ & & & \\ \text { After 150 min. } & 94.46 \pm 2.31 & 93.54 \pm 2.31 & 0.1284 \\ & & & \\ \text { Postoperative } & & & \\ \text { Immediate } & 95.01 \pm 2.38 & 92.30 \pm 2.35 & <0.0001 * \\ \text { 15 min. } & 94.96 \pm 2.35 & 92.36 \pm 2.32 & <0.0001 * \\ \text { 30 min. } & 94.88 \pm 2.55 & 92.24 \pm 2.15 & <0.0001 * \\ \text { 45 min. } & 94.69 \pm 2.33 & 94.46 \pm 2.33 & 0.7036 \\ \text { 60 min. } & 95.34 \pm 2.36 & 94.89 \pm 2.36 & 0.4632 \\ \text { 2 hours } & 95.54 \pm 2.21 & 94.90 \pm 2.67 & 0.3160 \\ \text { 3 hours } & 95.65 \pm 2.45 & 94.95 \pm 2 . .45 & 0.2732 \\ 4 \text { hours } & 96.56 \pm 2.25 & 95.89 \pm 1.99 & 0.2268 \\ \text { 8 hours } & 96.65 \pm 2.56 & 95.83 \pm 2.11 & 0.1810 \\ \text { 12 hours } & 96.86 \pm 2.18 & 96.78 \pm 2.65 & 0.8988 \\ \text { 16 hours } & 97.48 \pm 2.23 & 96.86 \pm 2.77 & 0.3436 \\ \text { 20 hours } & 97.13 \pm 2.15 & 96.21 \pm 2.34 & 0.1182 \\ \text { 24 hours } & 97.89 \pm 2.24 & 96.91 \pm 2.22 & 0.0941\end{array}$

*P-value $<0.05$

\section{Regarding VAS}

There was a statistically significant difference between the two groups regarding VAS score from immediate postoperative to after 4hours. At these times VAS was lower in group E than in group $\mathrm{N}$. The rest was statistically insignificant as shown in Table 5.

Table 5: Comparison between two groups according to VAS

\begin{tabular}{llll} 
VAS & Group E & Group N & p-value \\
\hline $\begin{array}{lll}\text { Immediate } \\
\text { postoperative }\end{array}$ & $1.68 \pm 0.43$ & $5.10 \pm 0.28$ & $<0.0001^{*}$ \\
30 min. & $1.81 \pm 0.22$ & $5.20 \pm 0.33$ & $<0.0001^{*}$ \\
1 hour & $2.15 \pm 0.44$ & $5.53 \pm 0.66$ & $<0.0001^{*}$ \\
2 hour & $2.23 \pm 0.66$ & $5.89 \pm 0.46$ & $<0.0001^{*}$ \\
3 hour & $3.21 \pm 0.88$ & $6.31 \pm 0.22$ & $<0.0001^{*}$ \\
4 hour & $3.64 \pm 0.80$ & $5.25 \pm 0.15$ & $<0.0001^{*}$ \\
8 hour & $4.08 \pm 1.02$ & $4.60 \pm 1.05$ & 0.0793 \\
12 hour & $3.26 \pm 0.77$ & $3.55 \pm 0.79$ & 0.1553 \\
16 hour & $2.80 \pm 0.53$ & $3.06 \pm 0.77$ & 0.1331 \\
20 hour & $2.97 \pm 0.44$ & $3.16 \pm 0.56$ & 0.1493 \\
24 hour & $2.00 \pm 0.62$ & $2.25 \pm 0.37$ & 0.0629
\end{tabular}

* Statistical significant difference between two groups (P-value $<0.05$ )
Anaesthetic and analgesic requirements

There is a statistically significant difference between the two groups regarding intraoperative anaesthetic - analgesic requirements and postoperative analgesia requirements which are lower in group $\mathrm{E}$ as compared with group N. Only four patients in group $\mathrm{E}$ needed rescue dose of analgesia compared to thirteen patients in group $\mathrm{N}$ as shown in Table 6.

Table 6: Comparison between intraoperative analgesic, anaesthetic and postoperative analgesic requirements

\begin{tabular}{|l|l|l|l|}
\hline & Group E & Group N & P-value \\
\hline Fentanyl(microgram) & $\begin{array}{l}122.67( \pm \\
43.16)\end{array}$ & $\begin{array}{l}198.23 \\
( \pm 85.44)\end{array}$ & $<\mathbf{0 . 0 0 0 1}^{*}$ \\
\hline Maintainedsevoflurane (\%) & $\begin{array}{l}2.2 \% \\
( \pm 0.4)\end{array}$ & $3.3 \%( \pm 0.3)$ & $<0.0001^{*}$ \\
\hline $\begin{array}{l}\text { Analgesia requirement in } \\
\text { postoperative 24 h }\end{array}$ & $4(13.3 \%)$ & $13(43.3 \%)$ & $\mathbf{0 . 0 2 1 9}^{\star}$ \\
& $/ 30$ & $/ 30$ & \\
\hline
\end{tabular}

Values are expressed as mean $( \pm \mathrm{SD})$ and percentage.

*P-value $<0.05$

\section{Regarding the incidence of adverse events in the postoperative period (Table 7)}

The results of the current study showed that:

- Eleven cases of hypoxaemia were observed in group N, but three cases were observed in the group E. This difference was statistically significant $(\mathrm{p}<0.05)$.

- None of the patients demonstrated hypotensive episodes ( $\mathrm{MAP}<60 \mathrm{mmHg}$ ) in both groups. None of the patients demonstrated bradycardia (HR $<60$ beat/min) in both groups.

- There were four reported cases of nausea in the group E, and fourteen reported cases in group N. Also, there were two reported cases of vomiting in group $\mathrm{E}$, and eight reported cases in group $\mathrm{N}$. These differences were statistically significant $(\mathrm{p}<0.05)$. 
Table 7: Comparison between two groups according to incidence of adverse events in the postoperative period

\begin{tabular}{|l|l|l|l|}
\hline Adverse events & Group E & Group N & P value \\
\hline Hypotension & 0 & 0 & - \\
\hline Bradycardia & 0 & 0 & - \\
\hline Hypoxemia & $3(10 \%)$ & $11(36.6 \%)$ & $0.0330 *$ \\
\hline Nausea & $4(13.3 \%)$ & $14(46.6 \%)$ & $0.0113^{*}$ \\
\hline Vomiting & $2(6.6 \%)$ & $8(33.3 \%)$ & $0.0235^{*}$ \\
\hline
\end{tabular}

$*$ P-value $<0.05$

\section{Discussion}

Despite high success rates of laparoscopic obesity surgeries, postoperative pain and PONV are still common problems. Effective postoperative analgesia and stable haemodynamics during the operation is an important factor affecting the complication rates of these patients. ${ }^{6}$

In this study, we recorded that reducing doses of opioids and anaesthetic drugs and adding esmolol to the anaesthesia protocol reduces PONV rates and postoperative pain complication rates without significant haemodynamic complications. The use of high doses of opioids in laparoscopy may delay recovery time, increase PONV and cause retention of urine. Beta blockers can be used effectively as alternative agents to reduce the need for opiates. Potential positive effects of beta blockers include haemodynamic stability, reduced need for anaesthesia and analgesics, reduced PONV rates, and reduced intubation stress. $^{7}$

Esmolol is the ideal beta blocker with a shorter half-life and cardiac selectivity. The effect starts quickly and is eliminated in a short time with a half-life of $9.2 \pm 2$ minutes. $^{8}$

Esmolol prevents adrenergic response in laryngoscopy and intubation / extubation and peritoneal irritation by insufflation of carbon dioxide during laparoscopy. The use of esmolol intraoperatively provides the opportunity to control the sympathetic organ response, thus reducing the consumption of $\mathrm{O}_{2}$ by heart muscle. A decrease in the response to nausea associated with surgery was also reported. ${ }^{9}$

The findings of Smith and colleagues support a comparison between esmolol and alfententil for the haemodynamic stability in a group of laparoscopic patients and reported that esmolol is a good alternative with fewer side effects. ${ }^{3}$

Chia et al investigated the effect of esmolol intravenously on the needs of analgesia during and after a total abdominal hysterectomy. Patients in the esmolol group (receiving an intravenous dose of $0.5 \mathrm{mg} / \mathrm{kg} / \mathrm{min}$, followed by infusion of $0.05 \mu \mathrm{g} / \mathrm{kg} / \mathrm{min}$ ) showed a significant reduction in the use of the PCA than in the control group over 3 days after surgery (received similar volumes of normal saline). ${ }^{10}$

Coloma and colleagues also compared esmolol with remifentanil to stabilize the haemodynamics in a group of patients undergoing laparoscopic gynaecological surgery and reported that it provides better haemodynamic stability. ${ }^{11}$

To substantiate our findings, Johansen and his colleagues reported similar results. They compared the effect of adding esmolol to the needs of fentanyl and $\mathrm{N}_{2} \mathrm{O}$ by $60 \%$ and found that esmolol greatly reduced the need for both agents. $^{12}$

In two different studies, Topcu et al and Wilson et al recorded esmolol reduced both need for propofol and remifentanil. ${ }^{13,14}$

Chia and colleagues noted that the addition of esmolol reduces the need of anaesthesia, postoperative analgesia and morphine use. ${ }^{10}$ Moon and colleagues report that the use of esmolol can shorten recovery time of PACU in patients undergoing gynaecological surgery. ${ }^{15}$

Bhawna and colleagues reported that adding esmolol to isoflurane in patients with abdominal operations may reduce the need for anaesthesia and postoperative analgesics. ${ }^{16}$

Öztürk and colleagues demonstrated that both PONV incidence and analgesic requirements 
are less in laparoscopic cholecystectomy patients when using esmolol. ${ }^{17}$

Stabilization of haemodynamics during and shortly after surgery is important to prevent PONV. Esmolol causes no abnormalities in blood pressure (low blood pressure or high blood pressure) and also facilitate usage of lower doses of opiates, which are known as triggers of nausea and vomiting. We believe that all those causes can reduce PONV rates in these patients. ${ }^{18}$

According to our results, the measured VAS score in PACU immediately after surgery and the next four hours was significantly lower in group $\mathrm{E}$ than in group $\mathrm{N}$. The incidence of PONV and hypoxia were also significant in group Ein postoperative 24 hours compared with group N. Similarly analgesic requirements in postoperative 24 hours was significantly lower in group $\mathrm{E}$ compared with group $\mathrm{N}$. Based on these results, we consider the use of esmolol during laparoscopic bariatric surgery for morbid obese patients to be useful compared to non-use of esmolol.

\section{Conclusion}

The use of esmolol adjuvant for anaesthesia of morbid obese patients undergoing bariatric laparoscopic surgery reduces the need of analgesics and anaesthetics with less postoperative pain, postoperative hypoxia and PONV without causing any haemodynamic instability.

\section{References}

1. Feld J, Hoffman W, Stechert M et al. Fentanyl or dexmedetomidine combined with desflurane for bariatric surgery. J Clin Anesth 2006; 18:2428

https://doi.org/10.1016/j.jclinane.2005.05.009 PMid:16517328

2. Adams J and Murphy P (2000): Obesity in anesthesia and intensive care. $\mathrm{Br} \mathrm{J}$ Anaesth 2000; 85: 91-108

https://doi.org/10.1093/bja/85.1.91

PMid:10927998

3. Smith I, Van Hemelrijck J, White PF. Efficacy of esmolol versus alfentanil as a supplement to propofol-nitrous oxide anesthesia. AnesthAnalg. 1991; 73:540-6. https://doi.org/10.1213/00000539-199111000$\underline{00005}$

PMid:1683182

4. White PF, Wang B, Tang J, et al. The effect of intraoperative use of esmolol and nicardipine on recovery after ambulatory surgery. AnesthAnalg. 2003; 97:1633-8. https://doi.org/10.1213/01.ANE.0000085296.0 7006.BA

PMid:14633533

5. Ritima D, Singh MR, Kaul TK, Tewari A, Oberoi R. Effect of intravenous esmolol on analgesic requirements in laparoscopic cholecystectomy. J Anaesthesiol Clin Pharmacol 2015; 31:375-9. https://doi.org/10.4103/0970-9185.161676 PMid:26330719 PMCid:PMC4541187

6. Lau H, Broks DC. Contemporary outcomes of ambulatory laparoscopic cholecystectomy in a major teaching hospital. World J Surg. 2002; 26:1117---21. https://doi.org/10.1007/s00268-002-6264-1 PMid:12209240

7. Frishman WH. beta-Adrenergic antagonists: new drugs and new indications. $\mathrm{N}$ Engl J Med. 1981; 305:500-6. https://doi.org/10.1056/NEJM1981082730509 $\underline{07}$

PMid:6114433

8. Sum CY, Yacobi A, Kartzinel R, et al. Kinetics of esmolol, an ultrashort acting beta blocker and of its metabolite. Clin Pharmacol Ther. 1983; 34:427-34.

https://doi.org/10.1038/clpt.1983.193

PMid:6617063

9. Miller D, Martineau R, Wynands J, et al. Bolus administration of esmolol for controlling the hemodynamic response to tracheal intubation: the Canadian multicentre trial. Can J Anaesth.1991;38:849-58. https://doi.org/10.1007/BF03036959

PMid:1683818

10. Chia YY, Chan MH, Ko NH, Liu K. Role of beta-blockade in anesthesia and postoperative pain management after hysterectomy. $\mathrm{Br} \mathrm{J}$ Anaesth. 2004; 93:799-805

https://doi.org/10.1093/bja/aeh268 PMid:15377583 
11. Coloma M, Chiu JW, White PF, et al. The use of esmolol as an alternative to remifentanil during desflurane anesthesia for fast-track outpatient gynecologic laparoscopic surgery. AnesthAnalg. 2001; 92:352.6 https://doi.org/10.1213/00000539-200102000$\underline{00014}$

12. Johansen JW, Flaishon R, Sebel PS. Esmolol reduces anesthetic requirement for skin incision during propofol/nitrous oxide/morphine anesthesia. Anesthesiology. 1997; 86:364-71. https://doi.org/10.1097/00000542-199702000$\underline{00011}$

PMid:9054254

13. Topçu I, Ozturk T, Tasyuz T, et al. The effects of esmolol on anesthetic and analgesic requirement. J Turk Anaesth Int Care. 2007; 35:393-98.

14. Wilson ES, McKinlay S, Crawford JM, et al. The influence of esmolol on the dose of propofol required for induction of anesthesia. Anesthesia. 2004; 59:122---6.

https://doi.org/10.1111/j.1365-

2044.2004.03460.x

PMid:14725513

15. Moon YE, Hwang WJ, Koh HJ, et al. The sparing effect of low dose esmolol on sevoflurane during laparoscopic gynecological surgery. J Int Med Res. 2011; 39:1861---9. https://doi.org/10.1177/147323001103900529 PMid:22117987

16. Bhawna, Bajwa SJ, Lalitha K, et al. Influence of esmolol on requirement of inhalational agent using entropy and assessment of its effect on immediate postoperative pain score. Indian $\mathrm{J}$ Anaesth. 2012; 56:535-41.

https://doi.org/10.4103/0019-5049.104570

PMid:23325937 PMCid:PMC3546239

17. Ozturk T, Kaya H, Aran G, et al. Postoperative beneficial effects of esmolol in treated hypertensive patients undergoing laparoscopic cholecystectomy. Br J Anaesth. 2008; 100:2114.

https://doi.org/10.1093/bja/aem333

PMid:18037672

18. Dereli N, Tutal ZB, Babayigit M, et al. Effect of intraoperative esmolol infusion on anesthetic, analgesic requirements and postoperative nausea-vomiting in a group of laparoscopic cholecystectomy patients. RevistaBrasileira de Anestesiologia, 2015;
65(2), 141-146.

https://doi.org/10.1016/j.bjane.2014.08.007 